\title{
The Necessity and Feasibility of Setting Privacy Right in Criminal Proceedings in China
}

\author{
Chunyan $\mathrm{Fu}$ \\ School of Political Science and Law \\ Baicheng Normal University \\ Baicheng, China 137000
}

\begin{abstract}
The privacy right is a legal concept widely existing in the legislation of the countries in the modern world, and the protection of privacy is a concrete manifestation of human rights guarantee. In a broad sense, based on the requirements of personal dignity of citizens, citizens should generally enjoy the right to be free from interference with and infringement on their personal privacy by others. The relevant provisions on this right in China's current legislation are not clear. They are only dispersely seen in relevant legislation, while a complete applicable system has not been formed. In criminal proceedings, the application process of investigative power, procuratorial power and judicial power may dispose of the information and body of the parties due to the need for case processing, especially those prosecuted in a criminal case have to face repeated inspections in the process of investigation, and the legislative design and practical application of these disposal ways may result in actual violation of the privacy rights of the applicable objects.
\end{abstract}

Keywords-criminal proceeding; privacy right; procedure application

\section{INTRODUCTION}

For the concept of privacy right, different scholars have their own understanding and interpretation and define them from different perspectives. There are also differences in the specific definitions of relevant legislation in various countries. According to the general statement, privacy right, as an important right in the human rights guarantee system, is a natural manifestation of the existence of basic human rights, and human's further refinement of their own interest concerns after guaranteeing the right to life, personal right, property right, and right to health... It emphasizes that not only the reasonable rights and interests need to be guaranteed from humans' survival and social aspects, but also the reasonable maintenance of personal dignity is required. These requirements have prompted the generation of relevant laws on the protection of rights to personal dignity, namely the reasonable protection of citizens' privacy rights. The progress of social civilization requires humans to pay attention to their own needs and take law as a means of realizing their natural rights. Law is becoming a concrete way for modern citizens to effectively realize their legitimate rights and interests. In the process of social civilization development, from the earliest maintenance of the rights to life and health to the manifestation of the rights to health, labor and education, acquiring the dignity in terms of selfprivacy is the actual reflection of improved legal awareness and corresponding requirements.

In China, related concepts on human rights protection, especially the related study on privacy rights, started late. At the same time, domestic scholars also have different views on the definition of privacy right. For example, some scholars believe that privacy right is a variety of physiological and psychological information that individuals are unwilling to disclose to others. From this perspective, privacy right belongs to a personality right of natural persons. Other scholars believe that privacy is a protection of private life, especially for individual's private information. In general, the privacy right should be recognized as a right of protecting the private information from being disclosed and violated, and from being enjoyed, spied and infringed by others, which should be naturally enjoyed by natural persons as a human. Such rights should be recognized by law and be allowed to protect from violations, and the limits of privacy violations in specific conditions and specific procedures should be strictly defined.

\section{PERFORMANCE OF THE INFRINGEMENT ON THE PRIVACY RIGHT OF THE PROSECUTED IN CRIMINAL PROCEEDINGS}

In criminal proceedings, the Criminal Procedure Law and related legislation have made specific provisions on the scope of powers and specific settings of the investigative organs, procuratorial organs, and judicial organs when exercising their respective functions and powers, and strive to strictly limiting the use of the right of prosecution by the public security and judicial organs within the statutory scope. However, there are still omissions in the current legislation, and human factors may exist in judicial practice, which make it inevitable to understand personal private information and acquire, collect and sort out it as relevant information of the case in the process of disposition of the parties involved, especially the prosecuted in criminal proceedings. In this process, there are often various investigations of legislative factors or personal factors, especially the compulsory measures, special investigations and related compulsory measures adopted by the investigation organs in the process of exercising the investigation power may cause certain violations of the privacy right of the prosecuted. 
First of all, in the process of interrogation, the staff of the state's specialized organs verbally question the prosecuted on the facts related to crime and ask him / her to make a statement on the question asked according to the law, which is a direct confrontation between the public power exercised by the public security and judicial organs on behalf of the state and the private rights of citizens. The prosecuted in criminal proceeding need to face indefinite interrogation at multiple stages of litigation, including investigative, prosecutorial and judicial organs. According to the provisions of the Criminal Procedure Law, in the face of interrogation, self-incrimination is unnecessary for the prosecuted, but he / she "should answer truthfully". That is to say, in our state's criminal litigation legislation and practical procedures, the prosecuted persons do not have the right to silence, namely the "right not to say". Although the Criminal Procedure Law also stipulates that "the interrogated person has the right to refuse to answer questions that are not related to the case", it is determined by the investigative organs whether the question is related to the case or not. This means that in the process of interrogation, no matter whether the question being questioned involves personal privacy, it is necessary to make an appropriate answer. It is true that there are complex multiple factors for why relevant rights including the right to silence have not been established, but it is not difficult to understand that the mainly factor is the actual need for solving the case. It's indispensable to consider legislation from this perspective, but the prosecuted is put in a situation where he / she cannot reject at all in practice. Although the personal privacy seems to be insignificant compared to the crime situation, and it is impossible to be the information that the investigative organs want to acquire. However, the process of telling private information that the prosecuted is unwilling to mention when his / her own rights and interests cannot be reasonably reflects the inequality of subjects in criminal proceedings. It seems difficult to achieve equality in the legal sense, and if the prosecuted fails to make timely and reasonable "true statement", there may be some personal threats, which also reflects the drawbacks of illegally obtaining confessions in criminal proceedings. The newly revised Criminal Procedure Law applies such a system as "duty lawyer" to this issue, and its effect remains to be tested by practice.

Secondly, in the process of search and inspection, the search is an investigation behavior of searching and inspecting the body, articles, residences and other relevant places of the suspect and the person who may conceal the criminal or the evidence of the crime according to by investigators to collect the evidence of the crime and seize the criminal suspect; the inspection is a physical examination on the personal injury, physical characteristics, special traces, intellectual development and physiological functions of the victim and the suspect involved in the case by the investigative organs. In terms of the application of search and inspection, only criminal victims can refuse personal inspections, and the application to other situations can all be enforced. However, when implementing the applicable procedures, it can be applied first and the procedures can be complemented later in emergencies. It is certainly a good way to seize the opportunity to obtain evidence and information, and solve the case, but it is difficult to grasp the extent of actual application in search and cause infringement. Relatively speaking, personal inspection may result in more direct privacy violations due to the physical contact with the subject being examined to obtain biometric materials such as fingerprints, saliva, blood, urine, and semen.

Thirdly, in terms of the application of a series of compulsory measures including technical investigations, due to their confidentiality, when conducting all-round monitoring and understanding of applicable objects in various ways, such as surveillance, eavesdropping, monitoring, interception of correspondence, telephone, electronic information, personnel exchanges, control of information, and the restrictions on the private space and private behavior of the prosecuted, it plays a role in ensuring the smooth conduct of the proceeding, but also caused violations of the privacy rights of the prosecuted.

\section{The NeCESSity OF SETting PRIVACY RightS IN CRIMINAL PROCEEDINGS}

Most of the traditional privacy settings focus on the protection of the personality right in terms of the sense of infringement, aimed to protect from others' infringement on the specific confidential information of the individual. That is to say, the privacy right is regulated from the perspective of civil law. Although the criminal procedure law guarantees the legal rights of the citizens involved in the proceedings, due to the need to solving the case, the degree of compliance with such regulations in the process of handling the case is limited, especially the protection of specific rights by legislation itself is mostly inclined to the realization of specific rights such as the right to defense, and the protection of such as personal information or personal dignity is not much recognized or applied in practice. Due to the compulsory application of judicial power in criminal proceedings, when the state's specialized organs exercise their power, the personal dignity of the individuals involved in the case may be violated in the process of filing, investigating, prosecuting, and adjudicating the criminal case. In particular, when investigating the criminal suspects, victims, etc. in the investigation stage, compulsory measures or other investigative measures are often applied, which may cause violations of the rights and interests of the parties to a certain extent, including the violation of personal dignity. It can be said that since criminal proceeding is featured by its natural existence, it determines the contradiction between the exercises of the powers by the state's specialized organs and the protection of the rights and interests of the parties involved in the proceedings is inevitable during the proceeding. Currently, relevant legislation on the protection of privacy rights in China's criminal law system is insufficient. There is no clear provision on privacy rights, the provisions concerning the protection of civil rights are mainly set to protect the litigious rights, and the provisions on personality rights are also very simple and rough, too, without further refinement into specific rights. Besides, the setting in privacy right is almost blank. Although the protection of the litigious rights of the prosecuted in criminal proceedings has been unprecedentedly improved from the 
perspective of legislative amendments, such right setting is not comprehensive. In most cases, only the protection of legitimate rights such as personal rights and property rights is focused on, while the privacy right that concerns personal dignity cannot be clearly manifested in legislation. We have to say that this still fails to fundamentally protect the personal dignity reflected by the privacy right in a rational way. It is true that for parties to the proceeding, especially as the prosecuted in criminal proceeding, since it involves the possibility of criminal offence, it is difficult to protect their rights in terms of personal dignity in the process of handling the case due to the need of solving the case, for that will make it more difficult to handle the case, and make the casehandling personnel "overcautious". In addition, in recent years, many local investigation organs also advocate "humanization" in the process of handling cases, so the requirements for personal dignity are not so strong. However, whether it is based on the possibility of criminal suspects' crimes or the humanized handling of the case-handling organs, the emergence of these factors is only a sporadic manifestation in individual cases. In most situations in practice, there will still be a large number of cases of disregarding the personal dignity of the parties involved. In the absence of specific laws and regulations, the protection of personal dignity is a way that can be chosen to implement or not by the case-handling personnel or the person involved in the case. In this sense, the setting of relevant privacy rights regarding personal dignity in legislation is necessary. Only when a certain system is formed can we fundamentally solve the violation of privacy rights in terms of personal dignity caused by the exercise of public power in practice. Of course, such a provision cannot be accomplished overnight, and its completion needs to be completed by further standardizing the current case handling procedures on the basis of consciousness transformation.

\section{CONSIDERATIONS OF FEASIBILITY FOR SETTING THE PRIVACY RIGHT PROTECTION SYSTEM}

\section{A. Qualifying the Privacy Right to Be Recognized from the Legislative Level}

At present, the recognition of privacy rights in China is very low. Based on the need for handling cases and the limitations of the degree of recognition, it is still in a twilight state in legislation. In the Constitution, the Civil Law and other codes, it is only stipulated in the name of personality right. This indicates that if the infringement of rights including personal privacy is only limited to civil handling, that is, the infringement met by equal subjects such as citizens and legal persons is in a general way. However, in judicial practice, acts that truly seriously infringe on the privacy right of individuals for several times are not only limited to the civil level, nor can they be regulated only by infringement damages. That is to say, the application of the state's public power does not seem to be restricted in such a provision. According to the requires the result of civil tort, the infringement on personal privacy in the course of criminal proceedings does not seem to be recognized, so the possibility of restriction or even the regulation on the doer can only be almost zero. As a comprehensive guarantee of civil rights, the Constitution that stipulates the rights and obligations of citizens in the broadest sense should make corresponding provisions on this, determine the necessity of its existence, and, at the possible time, stipulate this provision in the form of legislation in the relevant legal provisions of criminal proceedings.

\section{B. Expanding the Reasonable Scope of the Relevant Evidence Application System}

The rules for the exclusion of illegal evidence established in the relevant laws and regulations of criminal proceedings in China are still incomplete. There are many restrictions on the types of applicable evidence and the applicable principles. Under such circumstances, it is too early to require to identify the evidences involving the infringement on privacy right as illegal with this system and to exclude them. However, it can be reasonably expected that in the process of perfecting the illegal evidence system in China, its scope of application and its application situation will certainly be more reasonable. The system of illegal evidence exclusion stipulates that the relevant evidences on the infringement of citizens' privacy rights are in the excluding scope.

\section{Establishing a Reasonable and Effective Judicial Review System}

As an important manifestation of the awakening of citizens' awareness of protecting self-rights in the modern legal society, privacy rights should not only be reasonably protected by law, but should be fully respected on this basis. Specifically, it is necessary to impose stricter restrictions on the application of the public power, to prevent the abuse of power and the violation of civil rights caused by the randomness of law enforcement. The supervision here can be expressed as the establishment of a judicial review system for abuse of rights, to achieve timely supervision of many rights, including the privacy right.

The legislative purpose and value pursuit of criminal proceeding determine that in the application of criminal prosecution rights, it is necessary to pay equal attention to fighting crime and safeguarding human rights. This is not only a practical application and requirement of the basic principles of criminal procedure law, but also the actual embodiment of the transformation of rule by law thinking and the construction of rule by law system in China.

\section{CONCLUSION}

The Civil Law of China does not establish the privacy right as an independent personality right, but only takes an indirect method for protecting the privacy right of citizens by means of judicial interpretation and by maintaining the public order and good custom. Practice has proved that this indirect method of protecting privacy right is incomplete and not well-conceived. Therefore, in the Constitution and the forthcoming Civil Code, the privacy right should be clearly defined as an independent personality right of citizens. A protection system of citizens' privacy right should be formed, with the Constitution as a core, the Civil Code as a key, and criminal and administrative laws and regulations as auxiliary. 
The setting of criminal proceeding system and procedures may infringe on civil rights. In the process of prosecuting the prosecuted, the protection of the legal rights and interests of the prosecuted such as person and property rights, has been supported in relevant legislation, but is not comprehensive enough, and there is still room for improvement, especially in the process of facing the state's right of prosecution, the realization of citizens' confrontation may still have problems. In criminal prosecution, the protection of various rights is not comprehensive, especially in the definition and protection of the citizens' privacy rights, there is a gap in legislation, and there are practical needs for application in practice.

\section{REFERENCES}

[1] Li Jia. Study on the Constitutional Guarantee of the Rights of the Prosecuted in Criminal Cases [D]. Master thesis of Shanghai Normal University, 2018. (in Chinese)

[2] Qin Xu. On the Human Rights Protection of the Prosecuted in Criminal Proceedings [D]. Master's thesis of Lanzhou University, 2018. (in Chinese)

[3] Song Zhence. Study on the Abandonment of Criminal Litigious Rights - from the Perspective of the Prosecuted in China and the United States [D]. Doctoral thesis of China University of Political Science and Law, 2018. (in Chinese)

[4] Bai Dong. On the Rationality of the Target Model of Human Rights Protection in Criminal Proceedings [J]. Journal of Guizhou Renmin University, 2018. (in Chinese)

[5] Zhang Yifan. Study on the Protection of Criminal Suspects' Litigious Rights [D]. Master's thesis of Jilin University, 2017. (in Chinese) 